\section{Euthanasia: the role of the psychiatrist}

\author{
KRIS NAUDTS, CAROLINE DUCATELLE, JOZSEF KOVACS, KRISTIN LAURENS, \\ FREDERIQUE VAN DEN EYNDE and CORNELIS VAN HEERINGEN
}

\begin{abstract}
Summary Belgium has become one of the few countries in the world where euthanasia is legally allowed within a specific juridical framework. Even more unique is the inclusion of grounds for requesting euthanasia on the basis of mental suffering. Further refinement of the legal, medical and psychiatric approach to the issue is required in order to clear up essential practical and ethical matters.

Psychiatrists and their professional

organisations need to play a greater role in this ongoing debate and contribute from a clinical, scientific and ethical point of view.
\end{abstract}

\section{Declaration of interest None.}

In 2002 a new Act that legalised euthanasia in Belgium came into effect, with important implications for psychiatrists (Anonymous, 2002). Assessments of capacity by a psychiatrist may be requested for patients seeking euthanasia: these requests may relate to patients with or without mental disorder. Whether euthanasia becomes a significant practice in Belgium remains to be seen; however, it is clear that psychiatrists will become involved in this process because of their role in providing assessments of capacity. To our knowledge, Belgium is the first country where mental suffering stemming from either a somatic or a mental disorder is explicitly acknowledged in law as a valid basis for euthanasia. Although questions may arise concerning the other legal conditions included within the Act - for example, regarding the competence of the patient and whether the suffering is unbearable or the disease incurable - the Act means that euthanasia can be carried out on grounds of mental illness. The aims of this article are to clarify the current relationship between euthanasia, psychiatry and ethics in Belgium; to make comparisons specifically with the Dutch situation; and to present the most relevant issues arising from the wider debate in the professional literature. The article is based on a search for sources within the international medical literature, Belgian and Dutch legal scripts, and on public commentary on these documents.

\section{DEFINITIONS AND CONCEPTS}

In the Belgian Act euthanasia is defined as the act of deliberately ending another person's life at his or her request. Euthanasia can be performed only by a physician. The law permits only voluntary euthanasia, and tries to prevent the possible abuses that could occur if paternalistic non-voluntary (without explicit consent) and involuntary (done against the explicit wish to live or without asking the competent patient, but still in the latter's presumed interest) euthanasia were to be permitted. It avoids the usual active/passive distinction by considering only the active form to be euthanasia. These characteristics are all contentious aspects within the literature (Harris, 1985; Kuhse \& Singer, 1985; Rachels, 1986). If the doctor actively administers a drug to bring about the patient's death at the patient's explicit request it is called euthanasia, whereas if the doctor only prescribes or supplies the drug at the patient's request, it constitutes physician-assisted suicide. If the administration occurs actively and without explicit demand from the patient, it legally constitutes murder.

\section{PREVALENCE DATA}

Prevalence studies carried out in 20012002 revealed that, in Belgium, euthanasia represented $0.3 \%$ of all Belgian deaths, whereas physician-assisted suicide constituted $0.01 \%$ (van der Heide et al, 2003). In The Netherlands, euthanasia and assisted suicide were more frequently applied $(2.6 \%$ and $0.2 \%$ respectively; van der Heide et al, 2003). Specific data on assisted suicide in patients suffering primarily from mental disorder are available only from The Netherlands, where an estimated two to five patients a year receive assistance with suicide out of a total of 400000 patients receiving mental healthcare (Groenewoud et al, 1997). At the time of these studies, however, euthanasia and assisted suicide were still prohibited in both countries. Follow-up studies are needed to determine the change in prevalence data after decriminalisation.

\section{THE ACT}

In September 2002 the new Act legalising euthanasia in Belgium came into effect. Its conditions (Belgisch Burgerlijk Wetboek, $2003 a, b)$ are that the patient should be at least 18 years old, and competent and conscious at the time of the request; the request should be voluntary, well-considered and continuous (no minimum period of time is indicated, because the Act concerns patients with different life expectancies), and should not be the result of any kind of external pressure; the patient should be in a medically hopeless condition of constant and unbearable physical or mental suffering, which cannot be cured and which is a consequence of a severe and incurable disorder caused by accident or disease. The treating doctor has to ascertain that these conditions are fulfilled and has to confer with a second, independent physician to obtain his or her advice. The treating doctor is not bound by this advice. Normally, the treating doctor will assess the competence of the patient. However, when the treating doctor thinks that the patient will not die within the foreseeable future (i.e. the patient is not terminally ill), it is mandatory to consult a third doctor, namely a psychiatrist or a specialist in the disorder concerned. The request has to be made in writing, and all relevant data must be added to the medical file. If euthanasia is adopted, this is followed by a review of the case by a federal evaluation committee.

\section{DUTCH LEGISLATION AND INTERNATIONAL CONTEXT}

In The Netherlands euthanasia was decriminalised in April 2001 (Groenewoud 
et al, 2000; Anonymous, 2001). Unlike the Belgian Act, the Dutch legislation also considers physician-assisted suicide and it considers the issue of minors separately. In addition, the nature of suffering is not specified as physical or mental in The Netherlands Act. This means that, in both countries, euthanasia on grounds of mental suffering is legally possible, but only in Belgium is this stated explicitly. Furthermore, it is noteworthy that euthanasia was legalised temporarily (1996-1997) in Australia's Northern Territory, and laws allowing physician-assisted suicide for physically ill patients have been in place in Switzerland since 1937 and in Oregon, USA, since 1994.

\section{EUTHANASIA ON GROUNDS OF PHYSICAL SUFFERING: ROLE OF THE PSYCHIATRIST}

Major themes that emerged among patients asking for euthanasia are hopelessness, depressive symptoms, fear and concern, marked dependence on caregiving, demoralisation, pain and other symptoms, lack of social support and absence of religious beliefs (Cochinov et al, 1998; Emanuel et al, 2000; Haverkate et al, 2000; Kelly et al, 2002; Suarez-Almazor et al, 2002; Tataryn \& Chochinov, 2002). In neither Belgium nor The Netherlands is psychiatric consultation mandatory for physically ill patients. Prevalence data from The Netherlands show that in no more than $3 \%$ of all physician-assisted deaths is a psychiatrist consulted (Groenewoud et al, 1997). In these circumstances the main task of the psychiatrist is to assess the competence of the patient. Competence concerning treatment decisions signifies that the patient is able to communicate his or her decision, factually understand the situation and its consequences, and rationally assimilate the information (Appelbaum \& Grisso, 1988) This is only one possible, 'medical', definition of what constitutes competence. Neither the Belgian nor the Dutch Act defines competence. This issue is left to the opinion of the doctor concerned. A second important task for the psychiatrist is the detection and treatment of any psychiatric disorder. Third, the psychiatrist can attempt to make a thorough evaluation of the biopsychosocial situation of the patient and of possible influences from these different areas on the euthanasia request (Huyse \& van Thilburg, 1993; Grassi, 1997; Onwuteaka-Philipsen \& van der Wal, 2001).

\section{EUTHANASIA IN PATIENTS SUFFERING PRIMARILY FROM MENTAL DISORDER}

Euthanasia provided on the grounds of mental suffering is permitted by Belgian law if the patient is considered to be competent and the suffering is continuous, unbearable and untreatable, and is a consequence of a severe and incurable disorder (Anonymous, 2002). In The Netherlands the situation is similar (Anonymous, 2001).

\section{Context}

Data on euthanasia and physician-assisted suicide in patients who primarily have a mental disorder exist only in The Netherlands. A representative survey among Dutch psychiatrists by Groenewoud et al in 1995 demonstrated that the demand for assisted death in patients who suffered primarily from a mental disorder represented $3 \%$ of all requests for assisted death. In contrast to somatic medicine, where $37 \%$ of all requests are granted, in psychiatry this is seldom the case (with only $2 \%$ of requests granted). At least half of these patients also suffer from a severe somatic disorder, often in a terminal stage (Groenewoud et al, 1997).

The motivations behind requests for euthanasia among patients suffering from a mental disorder are broadly comparable with those cited in somatic medicine. They include absence of any hope of improvement $(68 \%)$, unbearable mental suffering $(58 \%)$, being a burden to others $(29 \%)$, pain or other physical suffering $(18 \%)$ and the loss of dignity (14\%). With regard to the conditions of the new Belgian legislation mentioned above, in $64 \%$ of the cases there were still psychiatric treatment options left that had been refused by the patient, in $70 \%$ of the cases the death wish was long-standing, in $86 \%$ the death wish had arisen without external pressure and in $32 \%$ of cases the patients were considered competent. The most frequent psychiatric diagnosis among patients requesting euthanasia was mood disorder. Personality disorders were categorised separately and were present in $64 \%$ of the cases, often in comorbidity with other disorders. Twentytwo per cent of the patients also had a somatic illness. The main reasons cited for refusal of a request by the physician were the presence of other therapeutic options, opposition in principle to euthanasia, and suffering thought of as not unbearable or hopeless. Other factors in the decisionmaking process not mentioned in the Belgian Act, apart from the legal requirements, are primarily the nature of the mental disorder, but also include the duration and character of previous treatment, duration and burden of treatment alternatives, the opinions of relatives, the patient's age and the threat of violent suicide (Groenewoud et al, 1997).

\section{Guidelines}

In most cases of euthanasia sought on grounds of mental suffering the psychiatrist is the treating doctor. This means that he or she maintains a therapeutic relationship with the patient, but is also the one who carries out euthanasia if the request is granted. This is clearly a highly complex situation, which has to be treated cautiously.

\section{Context}

The Belgian professional bodies do not provide guidelines on this matter. In comparison, in The Netherlands guidelines have been formulated by the Dutch Psychiatric Association (Nederlandse Vereniging voor Psychiatrie, 1998; Tholen et al, 1999). It is stated explicitly that the guidelines are meant for cases of mental disorder only, as defined by the DSM-IV (American Psychiatric Association, 2000), and thus not for cases of personal or social suffering. In addition, the nature and course of the mental disorder has to be taken into account. Extreme caution is recommended when taking euthanasia decisions for patients with a personality disorder. The guidelines state, as a fundamental principle, that the request for assisted suicide is essentially a plea for assistance with life; assistance with the ending of life is but a last, exceptional measure.

\section{Core conditions}

In the Dutch guidelines five core conditions are required. These conditions concur with the requirements set by Belgian law. First, the request for assisted suicide should have arisen independently of any external pressure. Patients who primarily have a mental disorder are at substantial risk of judging themselves to be a burden on their carers. 
The psychiatrist has to make sure that there is no external pressure towards the ending of life, either perceived subjectively or actual.

As a second condition, the request needs to be well considered. This means that the patient should be competent. However, the assessment of competence in a patient with a mental disorder is not straightforward, since the presence of mental disorder does not necessarily imply incompetence (Burgess \& Hawton, 1998; Nederlandse Vereniging voor Psychiatrie, 1998; Kerkhof, 2000). Some examples are patients with recurrent depressive or psychotic episodes who are in symptom-free periods of recovery; patients suffering from isolated psychotic symptoms such as hallucinations, who have preserved enough awareness of the illness; and certain cases of chronic depression which are not characterised by low mood and nihilism but rather by psychomotor disabilities and sleep difficulties (Nederlandse Vereniging voor Psychiatrie, 1998). Moreover, incompetence of the patient does not necessarily have to result in a refusal of the request for assisted death. However, this sliding standard of competence poses the risk of further paternalistic, non-voluntary euthanasia, as personal values of the psychiatrist might contribute to the judgement.

Third, the longing for death should be persistent. This is specified as the repeated and unequivocal expression of the request, to the physician as well as to a third party, over a period of at least several months. However, the request does not need to be in writing, because this might lead to patients forming an emotional attachment to their suicidal intent (Nederlandse Vereniging voor Psychiatrie, 1998). Fourth, the suffering must be perceived by the patient as unbearable. To evaluate this, the establishment of a profound and sustained therapeutic relationship between doctor and patient is essential (Nederlandse Vereniging voor Psychiatrie, 1998). Finally, suffering has to be beyond human aid. This signifies that there is no realistic therapeutic option left; that is, there is no remaining treatment option that gives a prospect of improvement within a reasonable period of time and that imposes no unreasonable burden on the patient. Essentially, this implies that all applicable biological, psychotherapeutic and social interventions should have taken place, according to medical understanding and to the personal values, standards and life aims of the patient (Nederlandse Vereniging voor Psychiatrie, 1998; Schoevers et al, 1998).

\section{Rules}

To help guarantee that these five intrinsic criteria are met, consultation with a second, independent psychiatrist is mandatory. If the treating psychiatrist refuses to provide assistance with suicide on grounds of principle, he or she has to inform the patient as soon as possible, thereby allowing the patient to approach another psychiatrist. Each part of this process must be put in writing and has to be passed on to the authorities (Nederlandse Vereniging voor Psychiatrie, 1998).

\section{MEDICAL AND ETHICAL ISSUES}

The acknowledgement of mental suffering as a valid ground for euthanasia, as established explicitly in Belgian law, is unique. With respect to both medical and ethical issues, the debate about the legitimacy of these grounds persists.

\section{Medical issues}

On a purely medical level, it is often argued that mental disorders are distinct from somatic disorders, and that the reasoning and practice adopted in somatic medicine should not therefore be simply applied in psychiatry. This argument is supported by the fact that the causes and psychopathology of mental disorders are often poorly understood and multifactorial (Kelly \& McLoughlin, 2002). The DSM-IV is the most widely used system of psychiatric diagnosis. Although much better than its predecessors, it is still in need of considerable improvement. In many cases its categories seem to be artificial, in that they do not represent valid disease entities. It is probable that mental health and disease are dimensional in nature, rather than categorical as is presumed in DSM-IV. This is particularly true for the categories of personality disorders, which are among the least valid and reliable of DSM categories (Helmuth, 2003). All these reasons contribute to a scientifically weak basis upon which to rest such an important decision as euthanasia. Moreover, there are still too few long-term follow-up studies in psychiatry to predict the natural course of a psychiatric disorder. Since many patients do not have all the characteristics necessary in order to fit into any of the typical categories of DSM, $20-50 \%$ of them in almost any diagnostic group are assigned to the 'not otherwise specified' category, and are usually excluded from clinical research (Helmuth, 2003). Because of this, it is often hard to predict what response might be expected from a certain treatment and when that response might occur (Schoevers et al, 1998; Kelly \& McLoughlin, 2002). Furthermore, prognosis is often uncertain, with the result that it is rarely possible to describe a mental disorder as incurable (Schoevers et al, 1998; Kelly \& McLoughlin, 2002; Helmuth, 2003; Sjöberg \& Lindholm, 2003). Thus, relative to somatic medicine, in psychiatric medicine there is greater uncertainty regarding the various aspects of the decision process and whether the legal requirements concerning euthanasia are met.

\section{Ethical issues}

The largest part of the discussion surrounds ethical issues. The first counter-argument against assistance with suicide in patients suffering primarily from a mental disorder is that one of the psychiatrist's basic responsibilities is to advocate for the vulnerable, disabled and infirm in our society and, when necessary, to protect them from themselves or others (Hamilton et al, 1997; Kissane \& Kelly, 2000). A classic manifestation of this task is the prevention of suicide. Assistance with suicide provided by the psychiatrist implies an attitude that is radically opposed to that medical goal (Burgess \& Hawton, 1998; Kerkhof, 2000; Kissane \& Kelly, 2000). Another important argument concentrates on the ambiguous notion of mental illness itself. If patients suffer in their environment and develop a mental disorder, it is difficult to ascertain whether the mental disorder and suffering are solely a natural reaction to an intolerable and/or hostile environment, or whether genuine mental disorder has ensued. Historical examples are the high numbers of suicide in unmarried mothers and gay men (once considered to be mentally ill) in social environments where they were not accepted. Thus, the term 'mental suffering stemming from mental disorder' is vague and hard to define, and the potential for abuse is serious. A final but recurring theme in the literature is a fear of gradual social acceptance of the practice of euthanasia, 
which might lead to a less careful decisionmaking process and to dealing less adequately with suicidal ideation and behaviour (van der Maas et al, 1996; Hamilton \& Hamilton, 2000; Onwuteaka-Philipsen et al, 2003).

\section{Potentially positive implications}

The main argument in favour of assistance with suicide for patients who primarily have a mental disorder arises from the area of suicide prevention. The demand for euthanasia by a patient means that life at that particular moment is unbearable to the patient and that something has to change. Thus, in the Dutch guidelines, the demand for assisted suicide is considered to be a demand for good, effective treatment. From this point of view, it is important to take this request seriously and open it up for discussion. In these circumstances a therapeutic relationship can be established in which space can be found to restore hope in the patient. When this has been sufficiently achieved, alternative treatment options may be considered by the patient (Nederlandse Vereniging voor Psychiatrie, 1998; Werth, 1998; Kerkhof, 2000).

Further arguments in favour are mainly based on compassion. Essentially, most patients suffering primarily from a mental disorder are physically capable of suicide, hence - some may argue - it is not really necessary to provide assistance. If no assistance is provided, however, the patient may be more likely to attempt suicide in lonely, difficult circumstances and in a risky and violent way. Moreover, such patients may run the risk of failing in their suicide attempt, and instead harm themselves seriously and permanently. Once the legal requirements have been met, assistance with suicide may create the opportunity for a more humane method of suicide (Burgess \& Hawton, 1998; Nederlandse Vereniging voor Psychiatrie, 1998; Kerkhof, 2000). Furthermore, prevention of violent suicide can be seen as a measure to protect people who might become accidentally involved in, and traumatised by, the patient's suicide (Nederlandse Vereniging voor Psychiatrie, 1998). However, the psychiatrist should rule out the possibility that the threat of a violent suicide is a manipulative gesture; to this end, the psychiatrist should rely predominantly on his or her own clinical experience (Kerkhof, 2000).

\section{DISCUSSION}

\section{Reactions from the medical world}

Reaction to the Belgian Act came, among others, from the World Medical Association (WMA), a federation of medical unions who stated that ethics should always prevail over the law, and that Belgian physicians refusing to cooperate with the new Act on euthanasia would be supported by the WMA (de Pape \& Selleslagh, 2003).

\section{Social responses}

From the Association of Care Institutions, the umbrella organisation of Catholic hospitals in Belgium, a disapproving and discouraging attitude towards euthanasia in its institutions was adopted: euthanasia of patients who were not terminally ill, patients in a coma who had supplied advance directives and patients experiencing mental suffering were all considered to be unacceptable (Vereniging van Verzorgingsinstellingen, 2002). Criticism also arose in the Catholic Church. Belgium's leading cleric condemned the euthanasia Act, calling it a token of the negation of the worth and dignity of man (Wouters, 2002). Since the vast majority of Belgian hospitals call themselves Catholic, the importance of these opinions should not be underestimated. Such responses are by no means atypical. In England and Wales, consultation by the joint committee examining the draft Mental Incapacity Bill resulted in a welter of critical responses from those who feared that it would permit euthanasia to proceed via the 'backdoor' (House of Lords \& House of Commons, 2003).

\section{Guidelines}

The Belgian professional bodies of psychiatrists have formulated no guidelines for the particular situation of a request for euthanasia on grounds of mental suffering. The law provides a framework for the approach to this situation, but a reply on the part of the professional world is lacking. We think it is essential that such guidelines are developed, in keeping with the state of affairs in The Netherlands. Moreover, consensus documents and protocols are needed concerning which therapies should be applied in specific disorders before euthanasia or assistance with suicide can be considered.

\section{Civil debate}

There has been ongoing, albeit little, debate about this controversial legislation.
Psychiatrists should, however, participate more and contribute from a scientific, ethical and clinical point of view.

\section{REFERENCES}

American Psychiatric Association (2000) Diagnostic and Statistical Manual of Mental Disorders (4th edn, Text Revision) (DSM-IV-TR). Washington, DC: APA.

Anonymous (200I) Wet euthanasie Nederland [The Netherlands euthanasia law] KB 12/04/2001. 'Wet toetsing levensbeeindiging op verzoek en hulp bij zelfdoding', Nederlands Staatsblad, 26 April, Artikel 194.

Anonymous (2002) Wet betreffende de euthanasie [Law concerning euthanasia]. Belgisch Staatsblad, 22 June, 28515-28520.

Appelbaum, P. S. \& Grisso, T. (1988) Assessing patients' capacities to consent to treatment. New England Journal of Medicine, 319, 1635-1638.

Belgisch Burgerlijk Wetboek (2003a) Verlengde minderjarigheid. Inleidende titel en boek I: Personen, Titel X, Chapter IV. http: / /www.staatsblad.be

Belgisch Burgerlijk Wetboek (2003b)

Onbekwaamverklaring. Inleidende titel en boek I: Personen, Titel XI, Chapter II. http: /www.staatsblad.be

Burgess, S. \& Hawton, K. (1998) Suicide, euthanasia and the psychiatrist. Philosophy, Psychiatry and Psychology, 5, 113-176

Chochinov, H. M., Wilson, K. G., Enns, M., et al (1998) Depression, hopelessness, and suicidal ideation in the terminally ill. Psychosomatics, 39, 366-370.

de Pape, N. \& Selleslagh, P. (2003) WMA: Ethiek heeft voorrang op wet. Artsenkrant, I516, 2

Emanuel, E. J., Fairclough, D. L. \& Emanuel, L. L. (2000) Attitudes and desires related to euthanasia and physician assisted suicide among terminally ill patients and their caregivers. JAMA, 284, 2460-2468.

Grassi, L. (1997) Psychiatric implications of euthanasia and assisted suicide in terminally ill patients. New Trends in Experimental and Clinical Psychiatry, 13, 127-132.

Groenewoud, J. H., van der Maas, P. J., van der Wal, G., et al (1997) Physician-assisted death in psychiatric practice in the Netherlands. New England Journal of Medicine, 336, 1795-180|.

Groenwoud, J. H., van der Heide, A., OnwuteakaPhilipsen, B. D., et al (2000) Clinical problems with the performance of euthanasia and physician-assisted suicide in The Netherlands. New England Journal of Medicine, 342, 55I-556.

Hamilton, N. G. \& Hamilton, C. A. (2000)

Therapeutic response to assisted suicide request. Issues in Law and Medicine, 16, 167-176.

Hamilton, N. G., Edwards, P. J., Crawshaw, R. S., et a (1997) Physician-assisted suicide in Oregon. American Journal of Psychiatry, I54, I326-1327.

Harris, J. (1985) The Value of Life. London: Routledge \& Kegan Paul.

Haverkate, I., Onwuteaka-Philipsen, B. D., van der Heiden, A., et al (2000) Refused and granted requests for euthanasia and assisted suicide in the Netherlands: interview study with structured questionnaire. BMJ, 32I, 865-866.

Helmuth, L. (2003) In sickness or in health. Science, 302, 808-810.

House of Lords \& House of Commons (2003) Joint Committee on the Draft Mental Incapacity Bill - First 
Report. UK Parliament, 17 November 2003. London: Stationery Office.

\section{Huyse, F. J. \& van Thilburg, W. (1993)}

Euthanasia policy in The Netherlands: the role of consultation-liaison psychiatrists. Hospital and Community Psychiatry, 44, 733-738.

Kelly, B. D. \& McLoughlin, D. M. (2002) Euthanasia, assisted suicide and psychiatry: a Pandora's box. British Journal of Psychiatry, 18I, 278-279.

Kelly, B., Burnett, P., Pelusi, D., et al (2002) Terminally ill cancer patients' wish to hasten death. Palliative Medicine, 16, 339-345.

Kerkhof, A. J. (2000) How to deal with requests for assisted suicide. Some experiences and practical guidelines from the Netherlands. Psychology, Public Policy, and Law, 6, 452-466.

Kissane, D.W. \& Kelly, B. J. (2000) Demoralisation depression and desire for death: problems with the Dutch guidelines for euthanasia of the mentally ill. Australian and New Zealand Journal of Psychiatry, 34, 325-333.

Kuhse, H. \& Singer, P. (1985) Should the Baby Live? Oxford: Oxford University Press.

Nederlandse Vereniging voor Psychiatrie (1998) Hulp bij zelfdoding door patiënten met een psychiatrische stoormis. Richtlijnen voor de psychiater (Physician assisted suicide by patients with a psychiatric disorder. Guidelines for the psychiatrist. English translation, May 2000). Utrecht: Dutch Psychiatric Association.

Onwuteaka-Philipsen, B. D. \& van der Wal, G. (200I) A protocol for consultation of another physician in cases of euthanasia and assisted suicide. Journal of Medical Ethics, 27, 331-337.

Onwuteaka-Philipsen, B. D., van der Heide, A., Koper, D., et al (2003) Euthanasia and other end-of-life decisions in the Netherlands in 1990, 1995 and 2001. Lancet, 362, 395-399.

KRIS NAUDTS, MD, Forensic Psychiatry Teaching Unit, Institute of Psychiatry, London, UK; CAROLINE DUCATELLE, MD, Department of Psychiatry, Gent University, Belgium; JOZSEF KOVACS, PhD, Institute of Behavioral Sciences, Semmelweis University Budapest; KRISTIN LAURENS, PhD, Institute of Psychiatry, King's College London, UK; FREDERIQUE VAN DEN EYNDE, MD, CORNELIS VAN HEERINGEN, PhD, Department of Psychiatry, Gent University, Belgium

Correspondence: Dr K. Naudts, Department of Forensic Mental Health Science, Institute of Psychiatry, PO Box 23, London SE5 8AF. Tel: +44(0) 207848 0680; fax: +44(0) 207848 0921 ; e-mail: k.naudts@iop.kcl.ac.uk

(First received 2I February 2005, final revision 13 June 2005, accepted 16 June 2005)

Rachels, J. (1986) Euthanasia and Morality. Oxford: Oxford University Press.

Schoevers, R. A., Asmus, F. P. \& VanTilburg, W. (1998) Physician-assisted suicide in psychiatry: developments in the Netherlands. Psychiatric Series, 49 $1475-1480$

Sjöberg, R. L. \& Lindholm, T. (2003) Decision-making and euthanasia. British Journal of Psychiatry, 182, 172.

Suarez-Almazor, M. E., Newman, C., Hanson, J., et al (2002) Attitudes of terminally ill cancer patients about euthanasia and assisted suicide: predominance of psychosocial determinants and beliefs over symptom distress and subsequent survival. Journal of Clinical Oncology, 20, 21344-2141.

Tataryn, D. \& Chochinov, H. M. (2002) Predicting the trajectory will to live in terminally ill patients. Psychosomatics, 43, 370-377.

Tholen, A. J., Berghmans, R. L., Legemaate, J., et al (1999) Physician-assisted suicide for a patient with a psychiatric disorder: guidelines for psychiatrists. Dutch
Association of Psychiatry. Nederlands Tijdschrift voor Geneeskunde, 143, 905-909.

Van der Heide, A., Deliens, L., Faisst, K., et al (2003) End-of-life decision making in six European countries: descriptive study. Lancet, 362, 345-350.

Van der Maas, P. J., van der Wal, G., Haverkate, I., et al (1996) Euthanasia, physician-assisted suicide, and other medical practices involving the end of life in the Netherlands, 1990-1995. New England Journal of Medicine, 335, 1699-1705

\section{Vereniging van Verzorgingsinstellingen (2002)}

VVI-Advies. Zorg voor een menswaardig levenseinde. De Standaard Online, 18 May. http: / /212.113.82.169/ Artikel/Detail.aspx?artikeld=dma20052002_00।

Werth, J. L. (1998) Using rational suicide as an intervention to prevent irrational suicide. Crisis, $\mathbf{1 9}$, 185-192.

Wouters, A. (2002) Kardinaal Danneels veroordeelt euthanasiewet scherp. De Standaard, 18 May. 